\title{
嚾 報
}

\section{會 員 動 静}

\begin{tabular}{|c|c|c|}
\hline 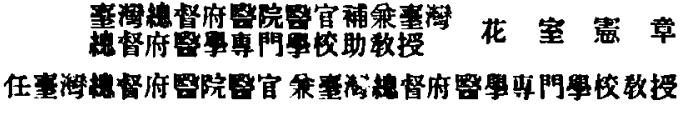 & 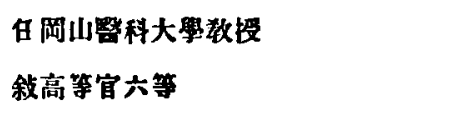 & 㚼 \\
\hline 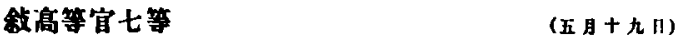 & 凮山圈科大學教授 & 烟 \\
\hline 文部者里校衞生宣 大西 永夯 郎 & 本俸入极体下睗 & （五月二+に \\
\hline 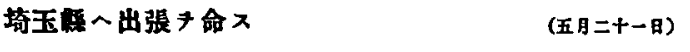 & 職拐俸金千五百圂下睗 & \\
\hline 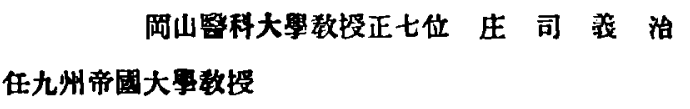 & 從七位黝六等 & 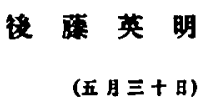 \\
\hline 敘高等官六等 & 文部省毁校苚生官 & 大四头夹 \\
\hline 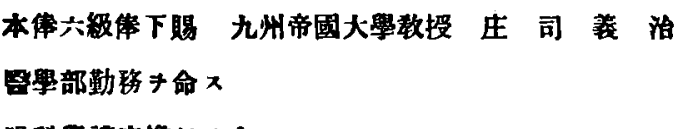 & 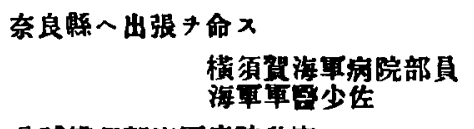 & 高 娍 \\
\hline 科 & 㞗補棈須賀海軍病院教官 & (大) \\
\hline
\end{tabular}

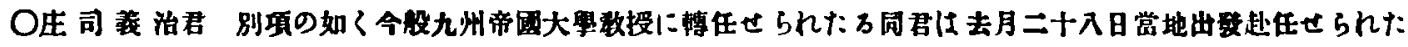
y

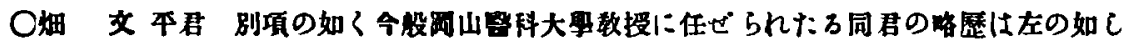

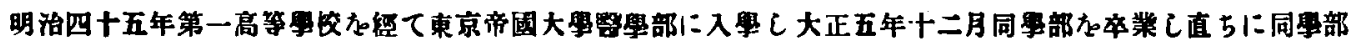
眼科数室に勤与

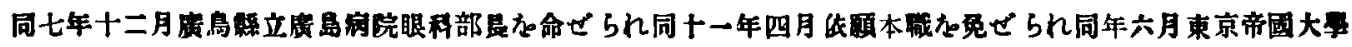

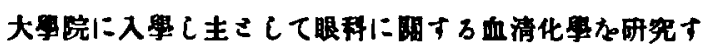

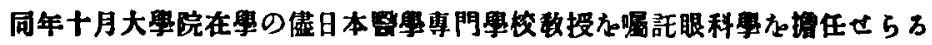

同十四年三月大悬院㴖期遍量

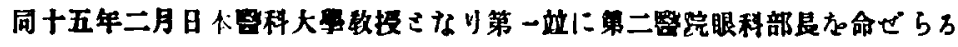

同年三月學博士の悬位飞授奥せらろ

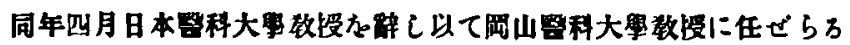

因に記寸君は去月二十七日着任さられけり

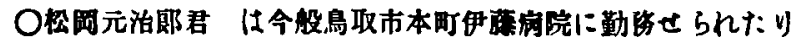

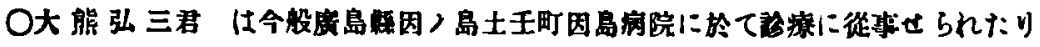



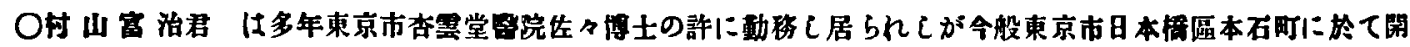
業せられた） 


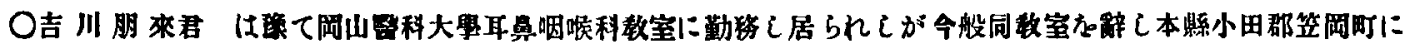
於て開業せられたり

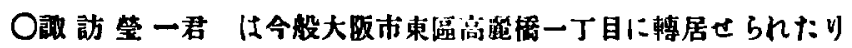

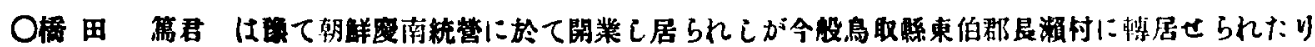

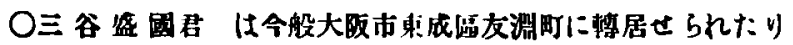

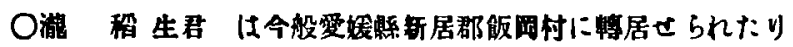

O正阙一董君は今般庙島市大手町に移䡣開業さられたり

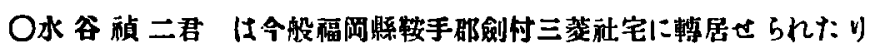

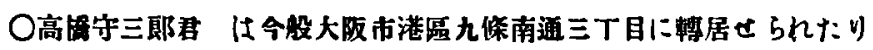

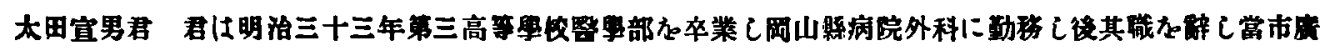

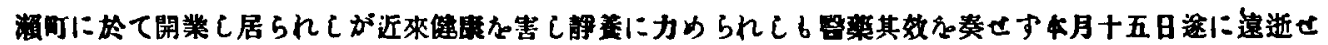

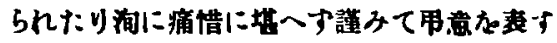

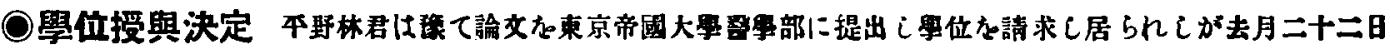

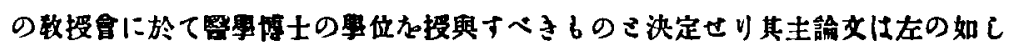

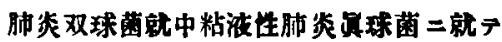

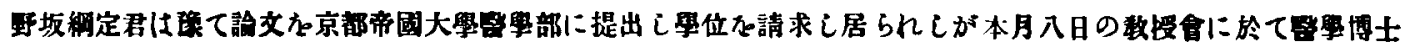
わ授奥すべるののさ決定ぜり其主論文は左の如し



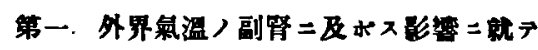

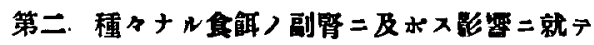

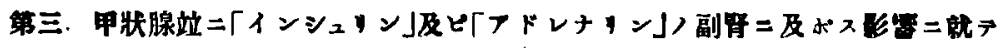

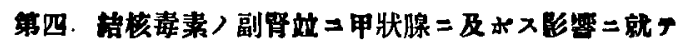

外二参考論文七秜

\section{○第三回岡山皮膚科汹尿器科地方會}

去了六月五日岡山醫大皮䖉科泌尿器科醫局に於て開催次の演話おり，終つて內山下 佐々岡に於て等親目を開催せり。

头回は來る十月二十三日(土曜)午挠二時よb開催すへし。

演 說 抄 錄
1. 陰蓝癌/ 2 例
江原猪知郎君

1. 榞某 71 男于






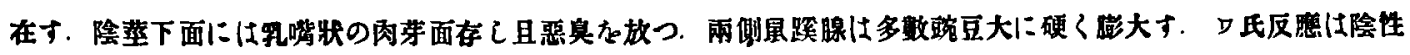
II $y$.

2. 難波某山点男于

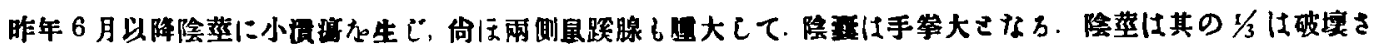

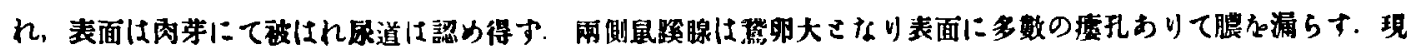

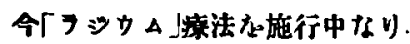

2. 陰部潰瘍性粟粒結核の1例

江原猪 知 郎君

小森某 27 男子

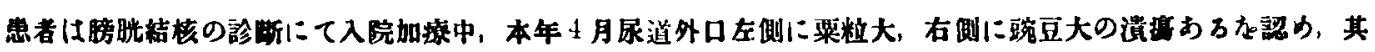

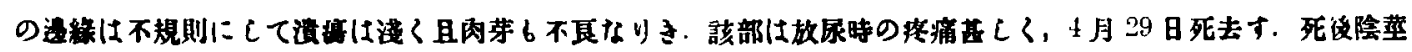



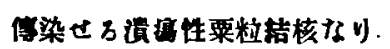

3.莘丸謢謨腫の 1 例

江原猪知郎君

\section{磁原某 34 思于}



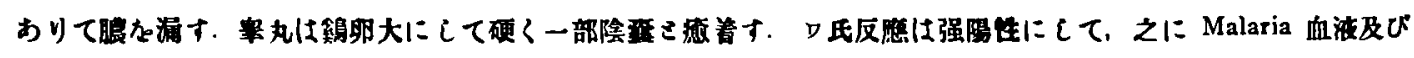

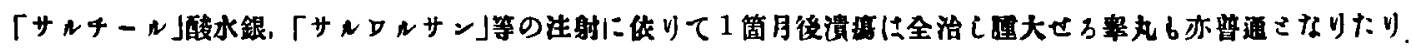
4. 腎性疼痛につきて
大道 直 一 君

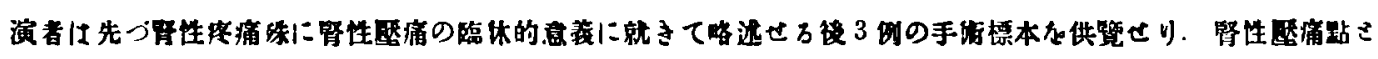

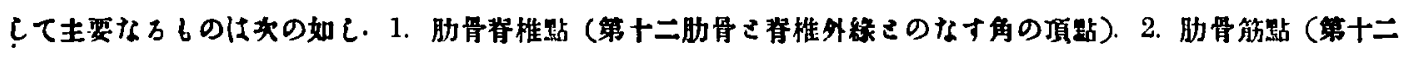

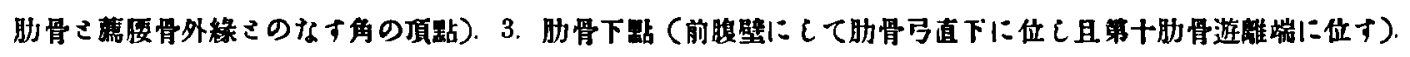

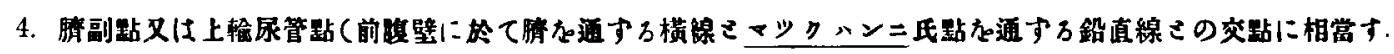

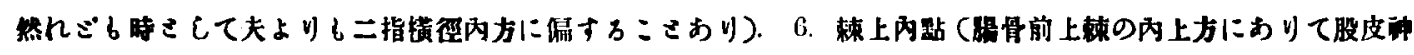

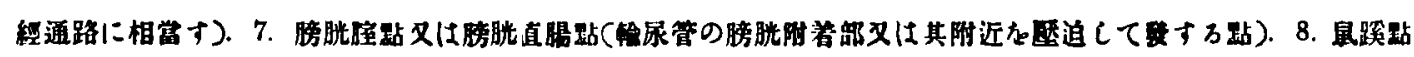

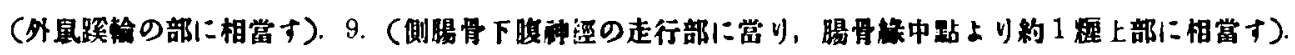

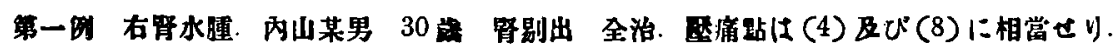

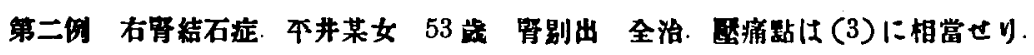

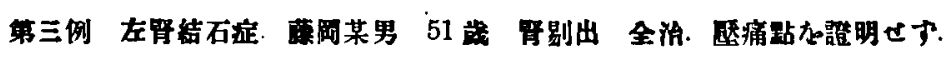

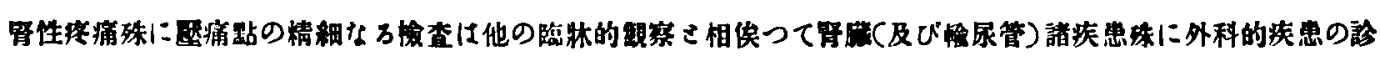

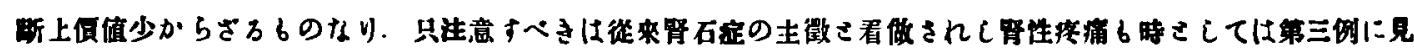
ろが如く全くこれな缺如する:さ即ちえなり。

5. Freyer 氏聶護腺剔出術に就て

內田茂雄君

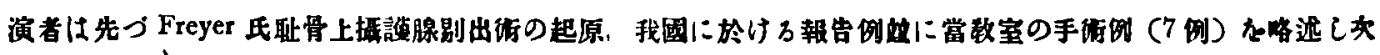

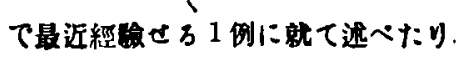


即5患者 65 戴，初診大正 15 年 3 月 10 日，手源 3 月 15 日，全治退院 4 月 17 日

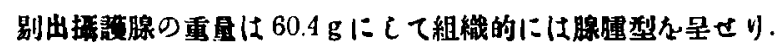

6. 泌尿器科消毒法に關する二三り示說 中川小四郎君

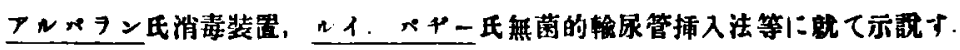

7.「ウロリトモク゚ラフィー」に就て 中川小四郎君 內田茂雄君

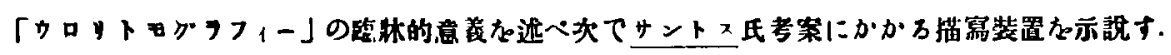

8. 偐胱丙異物ど結不i 大森大堂君

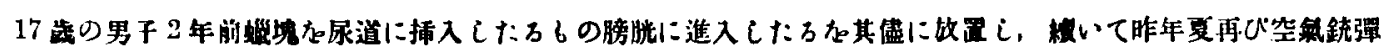

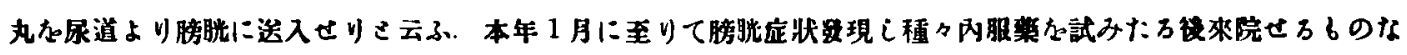

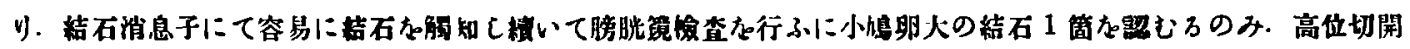

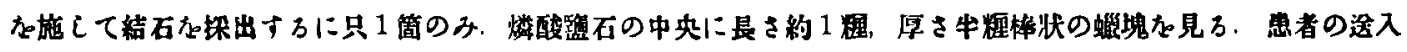

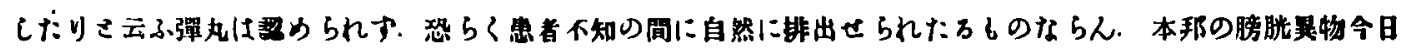
迄に約 50 例あり。

9. 带㶍つ 1 例 小池藤太郎君 患者高榙某 17 風山睡人



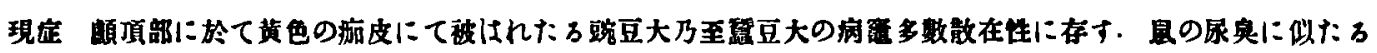

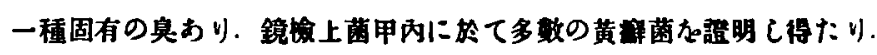

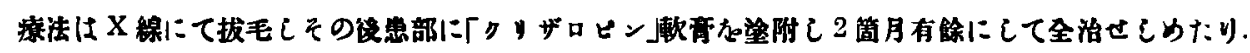

10. チェルス゚ース氏秃凔の 3 例 小池㭗太郎君

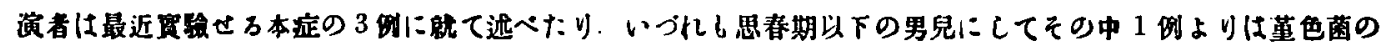

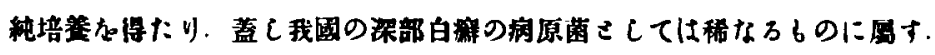

11. 種痘棈水疮疹つ 2 例 小池藤太郎君

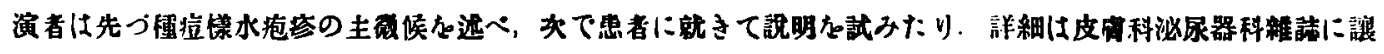
ろ.

12. 軟骨性母斑の 1 例 膫原晧君

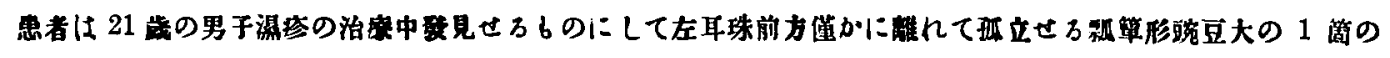

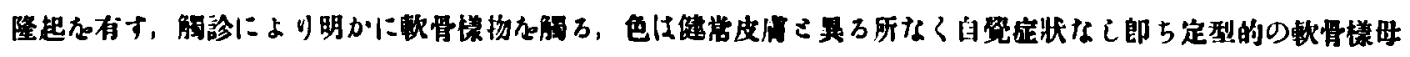
庭の 1 例なり.

13. 列序性母瑟の 2 例

滕原晧君

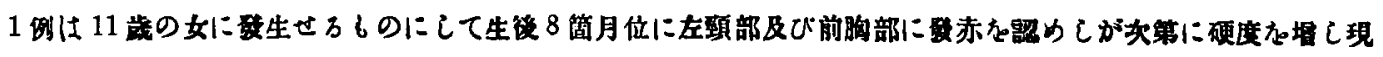

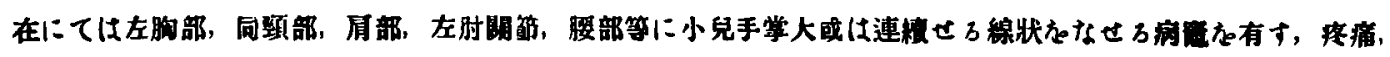




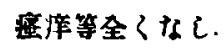

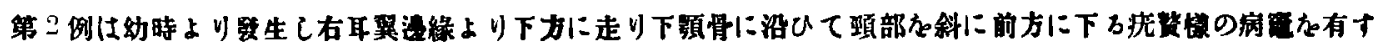
ろるのはり.

14. 扁平紅色苔解の 2 例

傣 原曋君

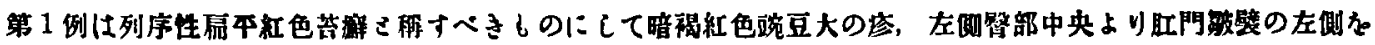

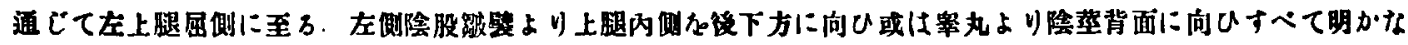

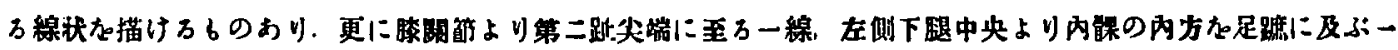

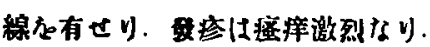

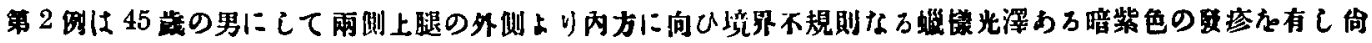

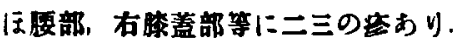

15. 片侧性顏面萎縮症の1例滕原晧 君

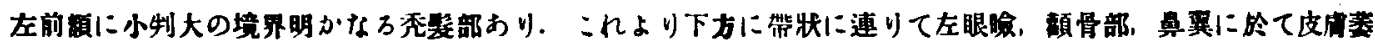

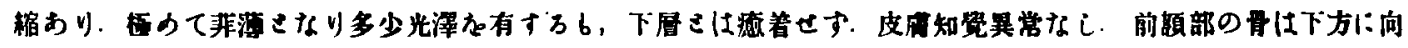



16. 負血性母斑D 1 例藤 原晧君

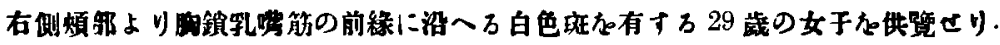

17. Bazin 氏硬結性紅斑の3 例（患者供覽）大道 直一君

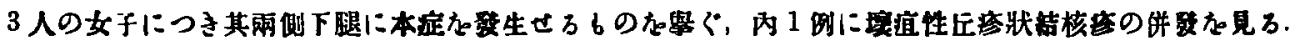

18. 攋に對する「レプロール」及び沃度「ナトリウム」泩射に就て

附. 濑患者治療經過數例背 道一君 原著に讓ろ。

19. 兄妹に登生せる汗孔角化症西茂雄君

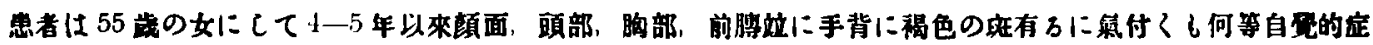
侯無し。

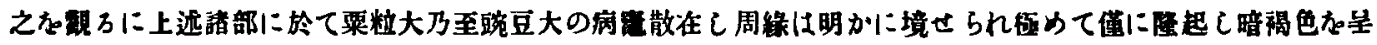

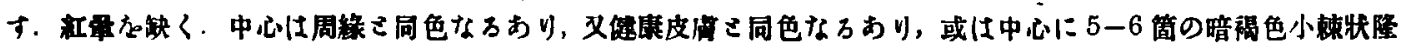
起艻有す。

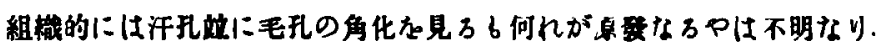

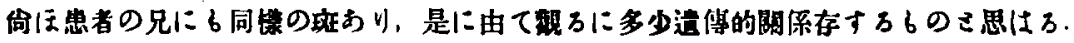
20. 微毒重威染の 1 例
内田茂雄君

患者奥田某 53 䊼初的 5 月 14 日

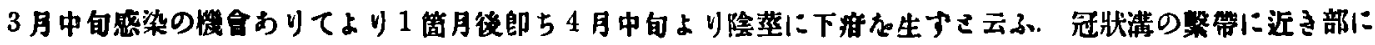




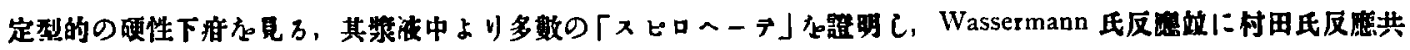
に强陽性か示す。

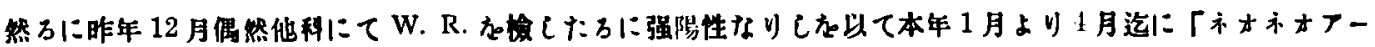
七ミン」3同注射さられ4月7日のW.R. は低然强陽性なりしさ云ふ。

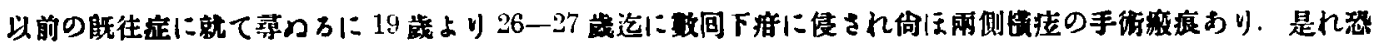

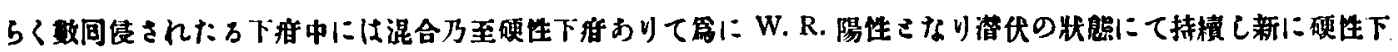
底がたるるのこ思はろ。
21. 驅徽療法所感の二三
皆見省吾君

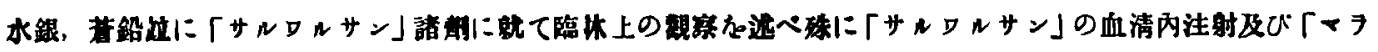

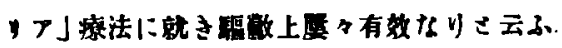

○國绦性學金議開催（International Congress of Sexuology） 本年十月十五日伯林に於て第一间

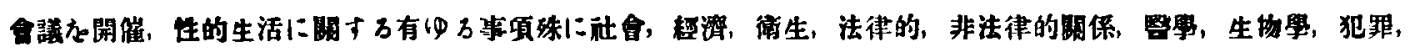

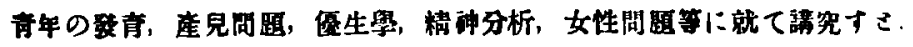

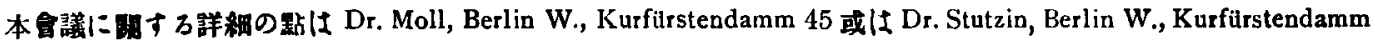
44 に申込まれた .

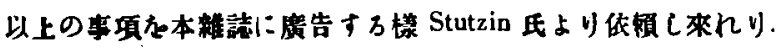

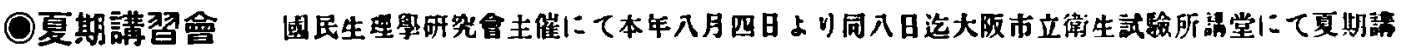
習合九開會す万由

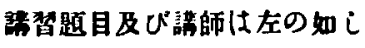

释替题目

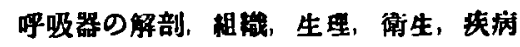

師

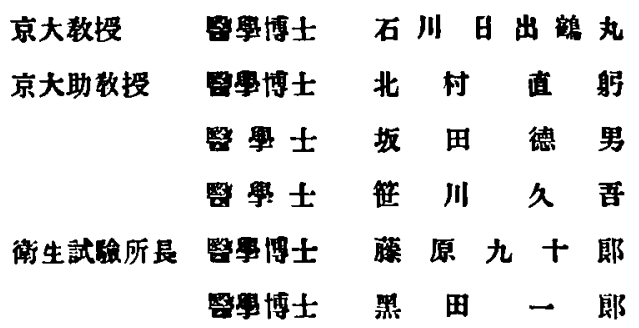

畕ほ申込期日は七月三十日．合最金六圆

新刊書

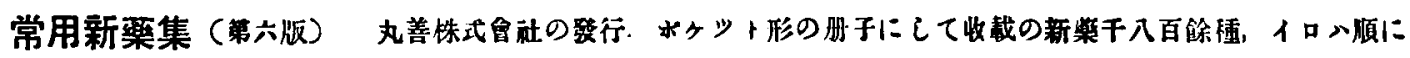

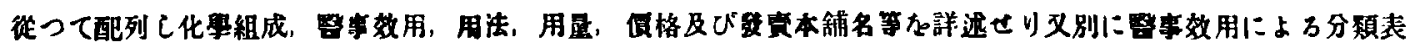

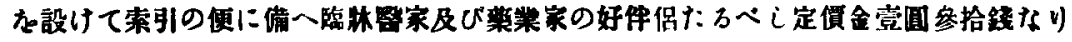

